\title{
Eco Smart City Method of Promoting Environmental Sustainability and Sustainable Development in an Industralised and Digitalized Society
}

\author{
Alexandra R. Harrington <arharrington@gmail.com> \\ NEW YORK, USA
}

Magdalena Stryja <magdalena.stryja@us.edu.pl> KATOWICE, Poland

\section{Introduction}

When starting to consider the ecological smart city ("eco smart city") as a method of promoting sustainable development, it is worth emphasising the interdisciplinary nature of this issue, which makes it difficult to discuss urban development in isolation from the environment and its protection. Many scientists and researchers emphasise that the idea of the smart city should be looked at in a holistic way. This approach requires a systematic approach to the elements and phenomena occurring within it, but it also suggests analysing the processes that shape it, taking into account the past, present and future. And here we enter a new, more and more commonly used terminology, i.e. smart city. ${ }^{1}$

The antecedents of the concept of smart growth can be found in Agenda $21,{ }^{2}$ an international document on sustainable development, which was adopted during the "Environment and Development Conference" on the initiative of the United Nations in 1992 at the Second Conference in Rio de Janeiro. The Agenda contains 21 Millennium Goals with a timeframe of 2000 to 2015. The document outlined how to develop, implement and enforce sustainable development programmes in local life. Agenda 21 defines sustainable development as "...social and economic development, which is the process of integrating political, economic and social activities while maintaining natural balance and permanence of basic natural processes

1 Agnieszka Sobol 'INTELIGENTNE MIASTA VERSUS ZRÓWNOWAŻONE MIASTA’ (2017) 320 Studia Ekonomiczne. Zeszyty Naukowe Uniwersytetu Ekonomicznego w 76.

2 Action Programme - Agenda 21 
in order to guarantee the possibility of satisfying basic needs of particular communities or citizens of the present and future generations". ${ }^{3}$

This idea carried through to the concept of smart growth and smart cities, the ideal version of which should be an eco smart city or a sustainable smart city. Such a city is a smart city, which acts in a sustainable way or is created in such a way. ${ }^{4}$ It is a city that, through the cooperation of many entities, by integrating infrastructure, services, production, education and recreation, ensures the most optimal functioning of the city as a whole. ${ }^{5}$ Future cities thus appear as a joint venture of many social partners: inhabitants, authorities, local entrepreneurs and other institutions, making use of the wealth of diversity of knowledge and the roles played by different local actors. $^{6}$

One of the definitions is proposed by Robert Horbaty, who calls an intelligent city a city that offers its inhabitants the maximum quality of life while minimising the use of resources through an appropriate combination of infrastructural systems, such as transport or energy transmission. ${ }^{7}$ Jeninifer Belissent, on the other hand, points out that a smart city uses information and communication technologies to make key services and urban infrastructure elements such as administration, education, security, public transport more efficient ${ }^{8}$. From the perspective of the present deliberations, the most desirable concept is that of the eco smart city, i.e. a city in which protection and concern for economic, social and spatial aspects extends and is equally important to protection of the environment, natural resources, air or climate, which can be seen, for example, in actions aimed at limiting carbon dioxide emissions, reducing water consumption or switching the energy sector to less harmful renewable sources. Following this line of thought, it can be said that the reason for the development of the eco smart city concept are the following: climate change, instability of the global economic system, urbanisation, digitalisation of life, greater expectations of the public in terms of quality of life, demographic trends

3 Agenda 21

4 Peter Newman, Sustainable Cities of the Future: The Behavior Change Driver, (2010) 11, 7 Sustainable Dev. L \& Pol'y.

5 ibid.

6 Walter Castelnovo, Gianluca Misuraca and Alberto Savoldelli, 'Smart Cities Governance: The Need for a Holistic Approach to Assessing Urban Participatory Policy Making' (2015) Social Science Computer Review <https://doi.org/10.1177/0894439 $315611103>$ Accessed 2 July 2021.

7 Cf. $<$ https://ideologia.pl/smart-city-jak-inteligentne-miasta-poprawiaja-zycie-mieszk ancow/> accessed 2 July 2021.

8 Cf. ibid. 
and growing social awareness of the need to take care of the natural environment for the benefit of our own and future generations.

In each configuration of the eco smart city, it is clear that there are significant connections between the ways in which law, regulation, policy and technology intersect to create the ideally functioning entity and the ability of a State in which such a city is located to fulfill the obligations undertaken by Member States of the international community through the 2015 Sustainable Development Goals (SDGs). As this chapter explains, the eco smart city is deeply rooted in the terms of the SDGs, and vice versa, such that achieving one would significantly further the achievement of the other. This was true when the SDGs were agreed to in 2015, however, in the continuously unfolding context of the Covid-19 pandemic and the design of post-pandemic recovery plans and solutions, the symbiosis in relationships has only been reinforced. Indeed, as discussed throughout Section III, which overlays the various SDGs and associated targets with lessons from the eco smart city model, the pandemic has shed further light on the need for interconnections that are environmentally and societally sound, technologically advanced and focused on perpetuating durable communities in which all are regarded as valuable members with voices, merits and contributions to make. This requires a complex set of legal, regulatory and technological tools, which the SDGs and eco smart city model can provide.

\section{SDG Background and History}

Adopted in September 2015 during a meeting of the United Nations (UN) General Assembly, the Sustainable Development Goals (SDGs) represent the second set of goals used by the international community to address the most pernicious and threatening issues facing it. ${ }^{9}$ To fully understand the SDGs, however, it is essential to view them as part of a history that began with the turning of the millennia.

In 2000, the UN General Assembly adopted the first such set of goals, the Millennium Development Goals (MDGs) in order to acknowledge the critical issues following the international community into the new

9 United Nations General Assembly, Transforming our world: the 2030 Agenda for Sustainable Development, A/RES/70/1 (25 September 2015). 
millennium. ${ }^{10}$ The MDGs were significantly fewer in number than the SDGs -8 overall - and have been criticised for being overly aspirational in nature rather than setting achievable and quantifiable standards. ${ }^{11}$ In an innovative step, the MDGs were given a lifespan, 15 years, during which to accomplish their mission. ${ }^{12}$ The MDGs were focused on poverty elimination, building partnerships, addressing gender issues, addressing communicable diseases and disease in general, improving maternal health, child health, advancing access to basic education, and promoting "environmental sustainability." 13 Each of these goals was accompanied by several targets to provide a more tangible layer for assessing implementation, although these were not as detailed as the targets set forth in the SDGs. ${ }^{14}$ Key to the topic of the Eco-Smart City was MDG 7 on environmental sustainability. In this MDG, the international community focused specifically on the importance of preserving forests and natural resources, combatting air pollution and carbon emissions, increasing access to drinking water and proper sanitation, and assisting those defined as "slum dwellers." 15

The MDGs established the pattern of international community acceptance of and efforts to implement what are essentially soft law mechanisms as part of national laws and policies, international and regional organization policies and undertakings, and international practice. ${ }^{16}$ However, they have been openly criticized for lacking enforcement and oversight mechanisms and for their generality, combined with their aspirational nature, which can be seen in the small number of targets used and the lack of calculable measures of implementation. ${ }^{17}$ When the MDGs were set to expire in 2015, official UN evaluations indicated that, although there had been some important successes, including in increasing access to drinking water, overall the MDGs had not been achieved. ${ }^{18}$

With the lessons of the MDGs in mind, the international community engaged in a multi-year and multi-stakeholder process of drafting the

10 United Nations Millennium Development Goals, <https://www.un.org/millenni umgoals/> accessed 2 July 2021; Alexandra R. Harrington, International Law and Global Governance: Treaty Regimes and Sustainable Development Goals Implementation (Routledge 2021).

11 See Millennium Development Goals, (n 10).

12 ibid.

13 ibid.

14 ibid.

15 ibid.

16 ibid; see also Harrington, (n 10).

17 ibid.

18 ibid. 
successor entities, ultimately the SDGs. The SDGs, encapsulated in the larger Agenda 2030 document adopted by the UN General Assembly, recognize the need to address the three pillars of sustainable development economic, social and environmental - as part of a concerted effort to address the most pressing issues facing global society in the short and longterm. ${ }^{19}$ This includes the recognition of the inherent connections with environmental issues that extend beyond the concept of environmental sustainability promotion as enshrined in the MDGs. ${ }^{20}$

In total, there are 17 SDGs, which are accompanied by 169 targets and several hundred indicators, keyed to specific targets and intended to provide methods of measuring their implementation at set intervals. ${ }^{21}$ The 17 elaborated goals range from poverty to education to infrastructure to environment and beyond and, as discussed below, ${ }^{22}$ there are areas of intersection between elements of each of these goals and the concept of the Eco Smart City.

\section{Intersections of the SDGs and Eco Smart Cities}

\section{SDG 1 - End poverty in all its forms everywhere}

The MDGs echo soundly throughout the parameters of SDG 1 in terms of the continued global goal of eradicating poverty, a goal that also underlies many aspects of the Eco Smart City. While Target 1.1 provides a definition of "extreme poverty," namely USD 1.25 per day, and sets the goal of eradicating extreme poverty by 2030 , Target 1.2 seeks to address all forms of poverty and allows for the use of a national definition of poverty as created by each State. ${ }^{23}$ Taken together, these targets are intended to set the floor of extreme poverty while at the same time allowing each State to define poverty levels above it commensurate with national standards. ${ }^{24}$ This can be seen as providing flexibility for the development phases of the Eco Smart City while at the same time endorsing the social benefit aspects of it in the short and long-term.

19 See Agenda 2030, (n 9).

20 ibid.

21 ibid.

22 ibid.

23 United Nations, Sustainable Development Goal $1<$ https://sdgs.un.org/goals/goal1 $>$ accessed 2 July 2021.

24 ibid. 
Target 1.4 provides that "By 2030, [States] ensure that all men and women, in particular the poor and the vulnerable, have equal rights to economic resources, as well as access to basic services, ownership and control over land and other forms of property, inheritance, natural resources, appropriate new technology and financial services, including microfinance." 25 There are many areas of law and policy implicated by this target, and it seems that many aspects of the Eco Smart City could be used as methods of fulfill these requirements, ranging from ensuring that all citizens have access to reliable services to providing citizens with access to technology and technological developments.

SDG 2 - end hunger, achieve food security and improved nutrition and promote sustainable agriculture

Target 2.1, "By 2030, end hunger and ensure access by all people, in particular the poor and people in vulnerable situations, including infants, to safe, nutritious and sufficient food all year round," provides a critical area in which the Eco Smart City can advance the SDGs by providing information on food needs and access to food services. ${ }^{26}$ By coordinating this type of information and attempting to ensure that cities are ecologically sustainable through efforts such as urban gardening, the Eco Smart City represents a way in which to advance Target 2.1 throughout an often overlooked and underserved population in terms of food production and access - those in urban areas, especially the urban poor.

SDG 3 - ensure healthy lives and promote well-being for all at all ages

Target 3.3, "By 2030, end the epidemics of AIDS, tuberculosis, malaria and neglected tropical diseases and combat hepatitis, water-borne diseases and other communicable diseases," ${ }^{27}$ was important in 2015 but, in the wake of the Covid-19 pandemic, has taken on an entirely increased sense of urgency in 2021. As has been observed in cities across the globe, the pandemic has spread rapidly in congested living and working areas, as well as those that

25 ibid.

26 United Nations, Sustainable Development Goal $2<$ https://sdgs.un.org/goals/goal2 $>$ accessed 2 July 2021.

27 United Nations, Sustainable Development Goal $3<$ https://sdgs.un.org/goals/goal3 $>$ accessed 2 July 2021. 
are hubs for travel and transportation. ${ }^{28}$ The lessons from the Covid-19 pandemic have yet to be fully concluded, however it is clear that there is an inherent tie between environmental degradation, the growth of zoonotic diseases, and the spread of these diseases. ${ }^{29}$ By focusing on Target 3.3 and increasing the ability of cities to use technology as a means to track and analyze upticks in illnesses, the Eco Smart City has a significant role to play in the achievement of the SDGs.

Concomitantly, the importance of Target 3.4, "By 2030, reduce by one third premature mortality from non-communicable diseases through prevention and treatment and promote mental health and well-being,"30 has been emphasized in the Covid-19 pandemic's impacts on mental health and the marked relationship between the imposition of social distancing, lockdowns and quarantines and declines in mental health statuses of populations across the globe. ${ }^{31}$ In this context, there is a direct tension between the mental health needs of members of a population and the legal policies generated by States to address the public health needs of the population as a whole. ${ }^{32}$ One of the key methods of overcoming the underlying elements of mental health stresses during the pandemic - namely, isolation - has been through the use of technology to connect patients with their mental health providers. ${ }^{33}$ This highlights a critical role that technology and the interconnectedness fostered by the Eco Smart City can play in the pandemic and post-pandemic recovery from the mental health perspective as well as the achievement of SDG 3. Similarly, the ability of physicians and healthcare providers to continue delivering at least basic levels of care to patients in the pandemic through technological capacities such as telemedicine allows for further progress toward implementing SDG 3 to be sustained in areas with technological capacity. ${ }^{34}$

Further, Target 3.9, "By 2030, substantially reduce the number of deaths and illnesses from hazardous chemicals and air, water and soil pollution and contamination," 35 highlights the importance of ties between environmental degradation and illness in a non-zoonotic capacity. Given the his-

28 See Global Pandemic Network Ecological Rights Working Group, Position Paper: Environmental Protection and Human Rights in the Pandemic (2021).

29 ibid.

30 (n 26).

31 See Global Pandemic Network, (n 28).

32 See ibid.

33 See ibid.

34 See ibid.

35 (n 26). 
toric role of cities as agents of pollution, leading to zoning and other legal regimes which attempt to regulate pollution in urban areas, and the tendency of urban populations to demonstrate significant illness rates, for example respiratory and cardiac illnesses, ${ }^{36}$ there is a direct connection between achieving Target 3.9 and effectively implementing the goals and function of the Eco Smart City.

SDG 4 - ensure inclusive and equitable quality education and promote lifelong learning opportunities for all

Education is the foundation for future generations. It determines the level of education in society, the awareness of citizens of their role in public life, and in the life of the State overall. Quality education is a guarantee of a better life, a decent job, a happy and fulfilling private life, and of full participation in social life. As SDG 4 highlights, this concept of education does not end at a certain age or with the attainment of a certain level of education, but rather is envisioned as something that exists throughout one's life.

The concept of universality in education begins in Target 4.1, "By 2030, ensure that all girls and boys complete free, equitable and quality primary and secondary education leading to relevant and effective learning outcomes," 37 and is supplemented by Target 4.2, "By 2030, ensure that all girls and boys have access to quality early childhood development, care and pre-primary education so that they are ready for primary education." 38 Recognizing the many forms education may take and the many skills needed by individuals and society, Target 4.3 provides "By 2030, ensure equal access for all women and men to affordable and quality technical, vocational and tertiary education, including university," 39 Target 4.4 provides "By 2030, substantially increase the number of youth and adults who have relevant skills, including technical and vocational skills, for employment, decent jobs and entrepreneurship," 40 and Target 4.6 provides "By 2030 , ensure that all youth and a substantial proportion of adults, both

36 Global Pandemic Network, (n 28).

37 United Nations, Sustainable Development Goal 4, <https://sdgs.un.org/goals/goal $4>$ accessed 2 July 2021.

38 ibid.

39 ibid.

40 ibid. 
men and women, achieve literacy and numeracy." ${ }^{41}$ Finally, Targets 4.5 and 4.7 directly address the potential forms of discrimination faced by members of society, especially vulnerable members of society, across all levels of educational access and opportunity and requires States to create meaningful ways to work around this. ${ }^{42}$

Only with a well-educated society can the implementation of the ecosmart city be successful. The young people of today should be seen as the future implementers of the smart city idea, and at the same time the need for education of those at all ages is essential for the implementation and acceptance of smart city-based technologies. ${ }^{43}$ From the perspective of climate change in particular, the introduction of environmentally friendly technology and the creation of spaces that are friendly to everyday life, raising awareness in society should begin with appropriate education.

At the same time, the ability of technology to connect students and educators at all levels has been emphasized during the Covid-19 pandemic, in which the majority of education has become online to some extent. ${ }^{44}$ This has created many benefits, particularly in terms of allowing students to keep up with lessons, advance within and graduate through their academic programs, and maintain social cohesion with their fellow students and teachers. ${ }^{45}$ Conversely, the reliance on technology for education - be it in the midst of a global crisis or as a means of providing temporary education during emergencies or in lieu of absences from school for illness - has brought to light a serious issue of access and equity. From the beginning of the pandemic onward, there was an assumption in many laws and policies that students and families would have the technological capacity to connect to classes and participate in lessons. ${ }^{46}$ This assumption has been proven incorrect in developed and developing States alike, and many students in urban settings as well as rural areas have found that they are further stigmatized by being unable to access the technology necessary to remain in school. ${ }^{47}$ In this context, the emphasis of the eco smart city on ensuring access to technology for all citizens of an urban area becomes extremely impactful for students and their families, educators, communities and States. Understanding this relationship and the ways in which it can

\footnotetext{
41 ibid.

42 ibid.

43 ibid.

44 See Global Pandemic Network, (n 28).

45 ibid.

46 ibid.

47 ibid.
} 
contribute to the many targets established under SDG 4 offers the ability to advance the achievement of the SDGs as well.

\section{SDG 6 - ensure availability and sustainable management of water and sanitation for all}

One of the core benefits of the eco smart city model is the ability to deliver basic services and resources to all citizens of the city, including water resources and hygienic sanitation. Thus, SDG 6 is particularly relevant in the eco smart city context and, at the same time, the eco smart city model can be seen as a method through which is achieve the terms of the SDG and associated targets.

Target 6.1, "By 2030, achieve universal and equitable access to safe and affordable drinking water for all," 48 addresses the needs of all populations, including those in urban areas, for sustainable and sustained water resources. As has been demonstrated in cities, especially large cities, during the Covid-19 pandemic, living in urban areas makes communities and especially vulnerable communities susceptible to water shortages and lack of access to water resources when there are disruptions in the water supply chain. ${ }^{49}$ The eco smart city model would assist States in fulfilling Target 6.2 through the use of technology and the encouragement of sustainable practices for the use of water resources. This also ties into the terms of Target 6.4, "By 2030, substantially increase water-use efficiency across all sectors and ensure sustainable withdrawals and supply of freshwater to address water scarcity and substantially reduce the number of people suffering from water scarcity, ${ }^{50}$ and, through the continued use of adaptive technologies and updated information capacities, would allow for the perpetuation of a sustainable city model from the perspective of water resource consumption and water scarcity potential. Relatedly, Target 6.3, "By 2030, improve water quality by reducing pollution, eliminating dumping and minimizing release of hazardous chemicals and materials, halving the proportion of untreated wastewater and substantially increasing recycling and safe reuse globally," ${ }^{51}$ can be advanced through the ecological and

48 United Nations, Sustainable Development Goal 6, <https://sdgs.un.org/goals/goal 6> accessed 2 July 2021.

49 See Global Pandemic Network, supra note 28.

50 (n 48).

51 ibid. 
technical aspects of the eco smart city model, in which increased awareness, transparency and technological capacity come together.

Target 6.2, "By 2030, achieve access to adequate and equitable sanitation and hygiene for all and end open defecation, paying special attention to the needs of women and girls and those in vulnerable situations," 52 correlates to the aims of promoting safe and efficient waste management services - as part of infrastructural services - that are responsive to the needs of the community at the same time as they are geared toward promoting environmentally friendly solutions.

SDG 7 - ensure access to affordable, reliable, sustainable and modern energy for all

When thinking of the eco smart city model, perhaps one of the most common areas of sustained improvement which comes to mind is the energy sector given the focus of the model on environmental and technological convergence for improved innovation. This convergence echoes in key elements of SDG 7, Target 7.1, "By 2030, ensure universal access to affordable, reliable and modern energy services," 53 and Target 7.3, "By 2030, double the global rate of improvement in energy efficiency." ${ }^{4}$ It must be admitted that the eco smart city model will not, without more, result in the latter target of increases in global energy efficiency. However, as cities which have adopted the eco smart city model into their frameworks, such as Amsterdam and Masdaru, UAE, demonstrate, the changes in energy use and consumption patterns within large urban areas have significant impacts and can act as drivers for the larger energy sector. ${ }^{55}$

SDG 8 - promote sustained, inclusive and sustainable economic growth, full and productive employment and decent work for all

Economic growth and decent work in the smart city at a time of overlapping phenomena: the fourth revolution, the global trend of decarbonisa-

52 ibid.

53 United Nations, Sustainable Development Goal 7, <https://sdgs.un.org/goals/goal $7>$ accessed 2 July 2021.

54 ibid.

55 See Newman, (n 5); Christian Iaione, The Right to the Co-City, 9 Italian J. Pub. L. 80 (2017). 
tion in the service of climate protection and environmental protection. Work is one of the greatest values in human life. Decent work, decently paid, is the source of human balance and the fuel that gives energy to establish a family, self-development, fulfilment of passions and joy in many aspects of life. It also brings with it individual dignity and mobility, especially for jobs in the technology sector, and also allows communities to benefit from the skills and expertise of their members. Full and productive employment and the ability to access decent work is critical to implementing the eco smart cities model at the foundational level in terms of design, regulation, construction and maintenance as well as the fundamental level in terms of the philosophy behind the model.

Given the necessary symbiosis between SDG 8 and the elements needed for the eco smart city model, it is perhaps not surprising that the majority of articulated targets for SDG 8 intersect. Target 8.1, "Sustain per capita economic growth in accordance with national circumstances and, in particular, at least 7 per cent gross domestic product growth per annum in the least developed countries," ${ }^{6}$ Target 8.2, "Achieve higher levels of economic productivity through diversification, technological upgrading and innovation, including through a focus on high-value added and labourintensive sectors," 57 Target 8.3, "Promote development-oriented policies that support productive activities, decent job creation, entrepreneurship, creativity and innovation, and encourage the formalization and growth of micro-, small- and medium-sized enterprises, including through access to financial services," 58 Target 8.4, "Improve progressively, through 2030, global resource efficiency in consumption and production and endeavour to decouple economic growth from environmental degradation, in accordance with the 10-year framework of programmes on sustainable consumption and production, with developed countries taking the lead," 59 and Target 8.5, "By 2030, achieve full and productive employment and decent work for all women and men, including for young people and persons with disabilities, and equal pay for work of equal value," 60 all relate to the foundational and fundamental elements of the eco smart city model in which there is a focus on sustainability of employment, community

56 United Nations, Sustainable Development Goal 8, <https://sdgs.un.org/goals/goal $8>$ accessed 2 July 2021.

57 ibid.

58 ibid.

59 ibid.

60 ibid. 
and individuals as well as on environmental concerns and technological development perse.

\section{SDG 9 - build resilient infrastructure, promote inclusive and sustainable industrialization and foster innovation}

Each of the targets listed under SDG 9 is of considerable importance as a separate objective and at the same time they are inextricably linked in the context of furthering infrastructure, industrialization and innovation as well as advancing the laws, policies and systems needed for the implementation of the eco smart city model. Without technology and innovation there will be no industrialisation, which in turn promotes industrialisation and innovation. All aspects of the smart city concept, better education, decent work, income growth, health care, economic growth, environmental protection, development and strengthening of scientific research, are highly dependent on investment in infrastructure, industrial development and investment in innovation.

Target 9.1, "Develop quality, reliable, sustainable and resilient infrastructure, including regional and transborder infrastructure, to support economic development and human well-being, with a focus on affordable and equitable access for all," 61 highlights that infrastructure should be durable and of good quality, it should be sustainable but at the same time reliable, it should give people equal access to it but at an affordable price. These are on the surface seemingly difficult to reconcile, let alone to achieve, and yet in many cities they have been turned into action and implemented. ${ }^{62}$ This has been achieved by launching a fundamental assumption that infrastructure, modern technologies and good management should form a coherent organism with the inhabitants. ${ }^{63}$ Further, it must be remembered that modern infrastructure influences environmental protection, where its intelligent systems, sensor networks, collect data and process them, continuously perform measurements, analyse them automatically creating messages that warn, inform, recommend, about failures, collisions, air quality, or an increased state of harmful substances. Thus, an intelligent city can monitor and react to undesirable phenomena, can

61 United Nations, Sustainable Development Goal 9, <https://sdgs.un.org/goals/goal 9> accessed 2 July 2021.

62 See, e.g., Newman, (n 5); Iaione, (n 55).

63 See ibid. 
identify their sources, can perceive and warn, and as a result counteract and prevent such phenomena in the future.

Target 9.2, "Promote inclusive and sustainable industrialization and, by 2030 , significantly raise industry's share of employment and gross domestic product, in line with national circumstances, and double its share in least developed countries," ${ }^{64}$ Target 9.3, "Increase the access of small-scale industrial and other enterprises, in particular in developing countries, to financial services, including affordable credit, and their integration into value chains and markets," 65 Target 9.4, "By 2030, upgrade infrastructure and retrofit industries to make them sustainable, with increased resourceuse efficiency and greater adoption of clean and environmentally sound technologies and industrial processes, with all countries taking action in accordance with their respective capabilities," 66 and Target 9.5, "Enhance scientific research, upgrade the technological capabilities of industrial sectors in all countries, in particular developing countries, including, by 2030, encouraging innovation and substantially increasing the number of research and development workers per 1 million people and public and private research and development spending" ${ }^{67}$ represent a holistic method of understanding the needs of individuals and communities as they strive for industrialization and innovation in sustainable and mutually beneficial ways. The considerations concerning infrastructure, sustainable industry and supporting innovation should be accompanied by a few examples of the implementation of the Smart City concept, where Smart Economy, Smart Living and Smart Governance remain in symbiosis with care for the environment and climate, and where the residents are not only the beneficiaries of intelligent solutions, but are also often their initiators. It is worth emphasising that a large role in the development of sustainable smart cities is played by social capital, which, unlike human capital, is collective in nature, since it defines a community, including interpersonal relations, and not the sum of individual units ${ }^{68}$.

64 (n 61).

65 ibid.

66 ibid.

67 ibid.

68 Aleksandra Kuzior and Bartosz Sobotka, 47 <https://www-arch.polsl.pl/wydzialy/ ROZ/ZN/Documents/smart\%20city\%202019/Rozdzia\%c5\%82\%203.\%20Aleksand ra\%20Kuzior,\%20Bartosz\%20Sobotka,\%20SPO\%c5\%81ECZNY\%20WYMIAR\%2 0SMART\%20CITY.pdf> accessed 2 July 2021. 
SDG 11 - make cities and human settlements inclusive, safe, resilient and sustainable

In creating and implementing the eco smart city model, one of the essential elements of law, policy and practice is that the entities being created can provide a place of protection and support for those living and working in them. This is perhaps obvious for any settlement area and even more so given the importance of all aspects of sustainability to the eco smart city model. Thus, SDG 11 represents a key nexus between the SDGs and the eco smart city, particularly for the inclusion and protection of all populations and communities living in such cities.

There is perhaps no better way of understanding this nexus than to examine the articulated targets for SDG 11, namely: Target 11.1, "By 2030, ensure access for all to adequate, safe and affordable housing and basic services and upgrade slums," 69 Target 11.2, "By 2030, provide access to safe, affordable, accessible and sustainable transport systems for all, improving road safety, notably by expanding public transport, with special attention to the needs of those in vulnerable situations, women, children, persons with disabilities and older persons," 70 Target 11.3, "By 2030, enhance inclusive and sustainable urbanization and capacity for participatory, integrated and sustainable human settlement planning and management in all countries," ${ }^{71}$ Target 11.6, "By 2030, reduce the adverse per capita environmental impact of cities, including by paying special attention to air quality and municipal and other waste management," 72 and Target 11.7, "By 2030, provide universal access to safe, inclusive and accessible, green and public spaces, in particular for women and children, older persons and persons with disabilities." ${ }^{73}$ Each of these targets represents a fundamental concern of the international community in adopting the SDGs and Agenda 2030, while at the same time represents a critical concern for inclusiveness, protection and responsiveness for all members of an urban community.

69 United Nations, Sustainable Development Goal 11, <https://sdgs.un.org/goals/goa 111> accessed 2 July 2021.

70 ibid.

71 ibid.

72 ibid.

73 ibid. 
SDG 13 - take urgent action to combat climate change and its impacts \& SDG 15 - protect, restore and promote sustainable use of terrestrial ecosystems, sustainably manage forests, combat desertification, and halt and reverse land degradation and halt biodiversity loss

At the heart of the eco smart city model is the understanding of how vital environmental preservation and conservation is for all of society, as well as the unique role that cities and urban areas plan in efforts to address climate change. Without this understanding, the model would be very much technology driven but would lack the ability to ensure that technology is used in a way that addresses the key issues facing local, national and international communities.

Taken together, SDG 13 on climate change, which is intended to function in conjunction with the United Nations Framework Convention on Climate Change system, and SDG 15 on life on land have generated a set of targets that inform - and can be implemented by - the eco smart city model. Target 13.2, "Integrate climate change measures into national policies, strategies and planning," 74 encourages the entrenchment of laws and rules relating to the eco smart city and climate change efforts in a way which offers these cities the opportunity to serve at the forefront of generating new and responsive governance systems alongside technology systems. Much the same is true of Target 13.3, "Improve education, awareness-raising and human and institutional capacity on climate change mitigation, adaptation, impact reduction and early warning," 75 which can be advanced through the lessons of the eco smart city model.

Additionally, SDG 15 sets out goals for many of the environmental challenges faced by city and urban settlement areas, namely, Target 15.1, "By 2020 , ensure the conservation, restoration and sustainable use of terrestrial and inland freshwater ecosystems and their services, in particular forests, wetlands, mountains and drylands, in line with obligations under international agreements," ${ }^{76}$ Target 15.2, "By 2020, promote the implementation of sustainable management of all types of forests, halt deforestation, restore degraded forests and substantially increase afforestation and reforestation globally," ${ }^{77}$ Target 15.3, "By 2030, combat desertification, restore

74 United Nations, Sustainable Development Goal 13, <https://sdgs.un.org/goals/goa $113>$ accessed 2 July 2021 .

75 ibid.

76 United Nations, Sustainable Development Goal 15, <https:/sdgs.un.org/goals/goa $115>$ accessed 2 July 2021.

77 ibid. 
degraded land and soil, including land affected by desertification, drought and floods, and strive to achieve a land degradation-neutral world," 78 and Target 15.4, "By 2030, ensure the conservation of mountain ecosystems, including their biodiversity, in order to enhance their capacity to provide benefits that are essential for sustainable development."79

SDG 16 - promote peaceful and inclusive societies for sustainable development, provide access to justice for all and build effective, accountable and inclusive institutional at all levels

SDG 16 is one of the fundamental elements of Agenda 2030 and SDGs overall in that it covers such important areas as the protection of life, health, combating violence against children, sexual violence and human trafficking, as well as ensuring access to justice and the rule of law. ${ }^{80}$ The concept of Smart Growth, which includes development, support for infrastructure, Smart Living and the Smart Economy, can only come about if the rule of law is taken for granted and the protection of life, health, human rights and the sense of security of the individual is an undisputed overriding good. Without a legal system that provides effective mechanisms of legal protection, without legal security of all areas in a sustainable way, the attempts to implement the concept of Smart City cannot have a chance to succeed.

SDG 17 - strengthen the means of implementation and revitalize the global partnership for sustainable development

The concept of wide-ranging partnerships is critical to SDG 17 and also to implementing the eco smart city model, which requires all aspects of innovation and consumption to work together. In particular, several aspects of SDG emphasise the ability of the eco smart city model to work in tandem with and promote the achievement of the SDGs. These include Target 17.7, "Promote the development, transfer, dissemination and diffusion of environmentally sound technologies to developing countries on favourable terms, including on concessional and preferential terms, as mutually

78 ibid.

79 ibid.

80 United Nations, Sustainable Development Goal 16, <https://sdgs.un.org/goals/goa 116> accessed 2 July 2021. 
agreed," 81 Target 17.16, "Enhance the global partnership for sustainable development, complemented by multi-stakeholder partnerships that mobilize and share knowledge, expertise, technology and financial resources, to support the achievement of the sustainable development goals in all countries, in particular developing countries," 82 and Target 17.17, "Encourage and promote effective public, public-private and civil society partnerships, building on the experience and resourcing strategies of partnerships Data, monitoring and accountability." 83

\section{Conclusion}

The concept of the eco smart city is constantly developing and this requires a certain amount of flexibility, which intersects well with the spirit and contents of the SDGs as soft law instruments that are intended to be implemented by each State in ways that advance the economic, social and environmental needs of the State's population and the international community. Indeed, the focus of the eco-city concept on "how cities can achieve a better environment through the reduction in air, water and soil pollution and smart waste generation" 84 and on incorporating "a wide range of approaches aiming to turn cities in environmentally sustainable places and at developing communities that respect . . nature and have sustainable behaviors" 85 corresponds directly to the terms and structure of the SDGs and Agenda 2030. This is true across the swathe of SDGs, although there are necessarily some which are cross-cutting in nature and have more firmly entrenched connections to the eco smart city model.

In promoting the method of environmental sustainability, sustainable development with the parallel implementation of the eco-smart city concept, the chronology of action must not be forgotten. Firstly, quality education, sustainable economic development and, as a result, decent work, which will thus be the natural outcome of such a smart policy. This is also directly linked to economic growth that is shaped in a sustainable way. The promotion of mobility is conducive to the development of an open, multicultural society, and contributes to the removal of mental barriers.

81 United Nations, Sustainable Development Goal 17, <https:/sdgs.un.org/goals/goa $117>$ accessed 2 July 2021.

82 ibid.

83 ibid.

84 Iaione, (n 55) at 89.

85 ibid. 
From the perspective of the development of smart cities, the implementation of Goal 4 should include appropriately constructed educational programmes, scholarships, training of teachers and academic staff, but also, above all, infrastructure that supports this. It is not only modern school or academic teaching, but the entire urban environment (parks, modern campuses, sports facilities, cultural zones, green zones, etc.) which will support the implementation of the postulate of high-quality education.

An economy based on modern, environmentally friendly technologies, with a high labour intensity rate, a productive economy providing jobs, supporting entrepreneurship and creativity are the basic goals that should guide governments in implementing the Smart City idea. According to Agenda 2030, over the next nine years governments should ensure full productive employment and decent work for all women and men, should strive to ensure employment for young people and people with disabilities. In parallel, programmes should be developed, based on the Just Transition concept, aimed at retraining workers currently employed in sectors related to coal mining. We must not lose sight of the fact that most of the workers currently employed in coal mines, for example, are highly skilled and specialised professionals in occupations such as welders, machine operators, crane operators, electricians. These are skills that can be successfully applied in the eco-industry, especially since they are possessed by workers who are tenacious, accustomed to hard work, resilient, unafraid of the challenges and risks they face on an almost daily basis in the mining industry.

SDG 16 is directly linked to SDG 5 - gender equality - and to SDG 17 partnership for the achievement of the 2030 Agenda goals, which together form a plan that is very difficult to implement in view of the political situation in the world, conflicts, human rights violations, the isolation of certain areas, and especially if a new challenge is added to this, namely the post-pandemic reality with which the whole world is confronted, and the struggle to stabilise this state of affairs will be spread over the coming years. SDG 16 has thus become even more wide-ranging and capacious, and if we try to put SDG 16 in a short definition, it can be characterised as the protection of the rule of law.

Finally, it must be noted that responses to the pandemic at the legal and policy levels have given rise, arguably with necessity, to a world in which connection and interconnection is a good that is at once intangible and yet highly sought after. This has impacted the ability achieve every aspect of the SDGs, from health to poverty reduction to gender protections to partnerships and beyond. The eco smart city model stands as a potential source of support as the global community emerges from the Covid-19 pandemic, 
seeks to address the core legal and scientific drivers of the pandemic and its fallout, and attempts to fulfil the obligations it undertook in 2015 as part of the SDGs. 